\title{
5
}

\section{FEDERALISMO E PLANEJAMENTO ORÇAMENTÁRIO INTERGOVERNAMENTAL}

O federalismo, como forma de organização dos Estados que prevê divisão territorial do poder, em que se permite a coexistência de mais de uma esfera de poder em um mesmo território, sob comando único, é uma solução para muitos países em que, dadas as suas peculiaridades, encontram nele uma fórmula capaz de harmonizar culturas e regiōes diferentes, além de usar a descentralização para tornar mais eficiente o atendimento das necessidades públicas.

No entanto, o ato de planejar, compatibilizando essas diversas esferas de poder, respeitando-se a autonomia dos entes que a compóem, de forma coerente e capaz de se unirem em torno de objetivos comuns, nunca foi tarefa simples em nenhuma das federações existentes, até mesmo porque o planejamento, no ambiente federativo, deve levar em consideração não apenas a questão territorial, mas também setorial. Trata-se, todavia, de questão urgente, e que tem de ser enfrentada, como já preconizava Alaor Caffé Alves há mais de 40 anos. ${ }^{1}$

O sistema de planejamento abrange subsistemas organizados em torno de planos hierarquicamente subordinados, como bem observa Nazaré Cabral. "Estes subsistemas podem ter origem espacial (a que correspondem os níveis nacional,

"Neste passo, urge enfrentar o problema de frente ao se considerar a possível incompatibilidade entre a prática do planejamento, exigindo progressivamente a integração corrente das decisões sobre a aplicação de recursos públicos (o que implica a racionalização crescente e interdependência dos diferentes níveis da ação governamental, de todas as esferas governamentais, horizontal e verticalmente consideradas) e o princípio da autonomia daquelas esferas governamentais, inscrito como característica essencial do federalismo" (ALVES, Alaor Caffé. Planejamento e federação. Algumas reflexões sobre seus princípios. Revista da Procuradoria Geral do Estado de São Paulo, p. 128). 
regional e local/municipal) ou sectorial (níveis nacional, sectorial, subsectorial)".2 Compatibilizar o planejamento orçamentário de médio prazo com o planejamento econômico e setorial, e com a agenda das políticas públicas, é um dos grandes desafios para a aplicação prática do planejamento orçamentário plurianual, como registram com muita propriedade José Álvarez e José Alegre. ${ }^{3}$

Conciliar autonomias administrativas, financeiras e políticas, em suas diversas faces, de entes federados cujos governantes são eleitos livremente, capazes de organizar sua administração, com competência legislativa própria, interesses conflitantes ${ }^{4}$ e, no mais das vezes, Poderes Executivo, Legislativo e Judiciário próprios, exige mecanismos jurídicos, administrativos e políticos de coordenação e cooperação bastante complexos e nada simples de serem implementados e executados, como já destacado. Como bem pontua Marrara, "o federalismo aumenta o potencial de conflitos de direito do planejamento", dada a pluralidade de vontades estatais dos entes políticos autônomos e com competências próprias, que não são divididas de modo perfeito, gerando inevitáveis conflitos jurídicos de competência. ${ }^{5}$

Entre as principais dificuldades, está a de estabelecer um sistema de planejamento orçamentário coerente, eficiente e com segurança jurídica. O processo de planejamento é sempre mais complexo nas organizações federativas do que nos estados unitários, como já observou Premchand, citando o exemplo da Alemanha. ${ }^{6}$

2 CABRAL, Nazaré da Costa. Programação e decisão orçamental. Da racionalidade das decisões orçamentais à racionalidade económica, p. 143, citando João Manuel Carvalho.

3 ÁLVAREZ; José Luís Ruiz; ALEGRE, José Caamaño. Tendencias en la gestión presupuestaria a nivel internacional, p. 25.

4 Como bem observado por Allan Moreira, "planejar em um ambiente federativo, seja qual for o viés tratado, (...) impõe o reconhecimento de que essas estruturas administrativas, com caráter autônomo, como é o caso de Estados e Municípios, coexistem em um ambiente institucional relativamente confuso e com interesses por vezes conflitantes, através do qual se delimitam suas respectivas competências e esferas de atuação" (MOREIRA, Allan. O federalismo cooperativo brasileiro e o problema do planejamento orçamentário: os repasses do FPE aos Estados-membros. Revista de Direito Constitucional e Internacional, p. 347).

5 MARRARA, Thiago. A atividade de planejamento na Administração Pública: o papel e o conteúdo das normas prevista no anteprojeto da nova lei de organização administrativa, p. 15. E identifica várias questôes decorrentes desses conflitos, como a de que o "direito administrativo do planejamento" precisa avançar no sentido de chegar às respostas, a solução para os conflitos horizontais (entre planos no mesmo nível federativo), verticais (entre planos de diferentes níveis federativos), como evitar sobreposição de processos de planejamento e que instrumentos seriam necessários para prevenir e solucionar esses conflitos.

6 PREMCHAND, A. Government budgeting and expenditure controls, p. 216: "Consideration of the totality of expenditure poses more problems in a federal arrangement than in a unitary form of government (...) In the Federal Republic of Germany, state governments are obliged to formulate their own financial plans and coordinate with federal plans". 
E a necessidade de compatibilização multilateral dos entes públicos é essencial para o desenvolvimento das açóes governamentais, uma vez sendo o planejamento uma exigência constitucional que delimita competências a serem cumpridas por todos e cada um deles, como bem observa Tomás-Ramón Fernández, referindo-se ao caso espanhol, nas relações entre o Estado e as Comunidades Autônomas. ${ }^{7}$

São diversas as características do Estado Federal que poderiam colocá-lo em contraposição à atividade estatal de planejamento. Bastaria considerar a origem histórica da forma federal do Estado, fruto da tentativa de fragmentar territorialmente o poder e, assim, coibir as possibilidades de abuso, para que se afirmasse sua incompatibilidade com qualquer tendência de centralização presente, por exemplo, na elaboração de planos de abrangência nacional. ${ }^{8}$ No entanto, esse argumento parece contrariar fatores fundamentais que, segundo Eros Grau, conduzem à centralização no Estado Federal contemporâneo, como a necessária unidade de ação governamental para assegurar sua posição em um cenário de competição internacional, a ampla atribuição de tarefas ao poder público, que exigem planejamento nacional para a aplicação de grande volume de recursos financeiros, e mesmo a coordenação de esforços para promover a segurança nacional. ${ }^{9}$

A descentralização do poder de legislar resulta na pluralidade de órgãos criadores de normas, o que possibilita uma regulamentação diferente para cada região, de modo a "não permitir que o mesmo indivíduo crie as normas da ordem central e as normas das diferentes ordens locais". ${ }^{10}$

Essa distribuição, com consequente descentralização, das competências legislativas, em que uma pluralidade de legisladores atua criando normas para cada uma das ordens jurídicas parciais, torna a atividade de planejamento orçamentário - veiculada no Brasil por normas de âmbito nacional, mas também, e principalmente, por normas próprias de cada uma das esferas de governo -, uma das mais

FERNÁNDEZ, Tomás-Ramón. La planificación económica, camino de libertad. In: BAQUER, Sebastián Martín-Retortillo Baquer; LAFUENTE, Antonio Martínez (Coord.). Estudios de derecho y hacienda: homenaje a César Albiñana García-Quintana, v. I, p. 74.

8 GRAU, Eros Roberto. Planejamento econômico e regra jurídica, p. 49 e seguintes.

9 GRAU, Eros Roberto. Planejamento econômico e regra jurídica, p. 51.

10 É o sentido dinâmico da descentralização, a que se refere Hans Kelsen: "Recorre-se em geral à descentralização justamente porque ela permite que a mesma matéria seja regulamentada de modo diferente para diferentes regiōes. Portanto, será preferível não permitir que o mesmo indivíduo crie as normas da ordem central e as normas das diferentes ordens locais. Será preferível ter diferentes indivíduos atuando como órgãos criadores de Direito das diferentes ordens parciais e, desse modo, evitar a união pessoal dos órgãos das diferentes ordens" (KELSEN, Hans. Teoria geral do direito e do Estado, p. 441-442). 
difíceis de compatibilizar e, especialmente, de promover a adequada coordenação, tendo em vista que a atividade planejadora, mais do que outras, exige unidade de propósitos em torno de objetivos comuns.

Esse argumento é reforçado pelo fato de que as competências constitucionalmente atribuídas a cada ente não são completamente nítidas a não ser a partir de um número mais restrito de atividades. Dan Stegarescu, em análise do caso alemão, mostra que não há critérios claros para a distribuição da maior parte das competências entre as várias esferas de governo, o que acaba levando-as para a alçada do governo central. ${ }^{11}$

Isso também é válido no Brasil, onde as grandes disparidades de diversas naturezas existentes na federação brasileira tornam inviável uma distribuição de competências exclusivas para as diversas políticas públicas no plano constitucional. Muitas delas exigem coordenação e cooperação entre os vários entes federados, tanto no aspecto da arrecadação e partilha de receitas quanto na execução, com compartilhamento de recursos materiais e humanos, e também na regulamentação e fiscalização. Ainda que a Constituição em vários casos delimite competências, e a legislação infraconstitucional especifique as atribuições de cada uma, dificilmente há detalhamento necessário e suficiente para atender com precisão a todas as situações, o que se reflete no aspecto orçamentário, gerando dificuldades na orçamentação, tanto a curto quanto a médio prazo.

Coordenação e cooperação referem-se a conceitos cujos significados são bem expostos por Bercovici, sendo de todo pertinente reproduzir seu texto para compreendê-los.

"(Coordenação) é, na realidade, um modo de atribuição e exercício conjunto de competências no qual os vários integrantes da Federação possuem certo grau de participação. A vontade das partes é livre e igual com a manutenção integral de suas competências: os entes federados sempre podem atuar de maneira isolada ou autônoma. A coordenação é um procedimento que busca um resultado comum e do interesse de todos. A decisão comum, tomada em escala federal, é adaptada e executada autonomamente por ente federado, adaptando-a às suas peculiaridades e necessidades. A materialização da coordenação na repartição de poderes são as competências concorrentes. A União e os entes federados concorrem em uma mesma função, mas com

11 "Assuming that apart from a few original tasks of central and local governments, there are no clear criteria for the distribution of most functions among different levels of government, he predicts that particularly competencies of state governments tend to be attracted by the central government over time. Apart from this, as a consequence, the delimitations of areas of central and state government activity are expected to become increasingly blurred" (STEGARESCU, Dan. Centralizing tendencies in the public sector in Germany, p. 10). 
âmbito e intensidade distintos. Cada parte decide, dentro de sua esfera de poder, de maneira separada e independente, com a ressalva da prevalência do direito federal. Esse tipo de repartição é o previsto pelo art. 24 da Constituição de 1988”. ${ }^{12}$

Completa mais à frente, citando o constitucionalista espanhol Enoch Alberti Rovira:

“'La cooperación, en sentido estricto, se diferencia cualitativamente de estas anteriores relaciones, al consistir propiamente en una toma conjunta de decisiones, en un coejercicio de las competencias, y, consiguientemente, en una corresponsabilización de las actuaciones realizadas bajo tal régimen. Una determinada función o competencia no se realiza ya de forma autónoma y separada por cada instancia, con todos los límites externos de aplicación al caso, sino de forma conjunta, de modo que tal función o competencia, para que se traduzca en concretas actuaciones, sólo puede ser ejercida conjuntamente por varias partes, que deben actuar mancomunadamente'. $\mathrm{Na}$ cooperação, nem a União nem qualquer ente federado podem atuar isoladamente, mas todos devem exercer sua competência conjuntamente com os demais. $\mathrm{Na}$ repartição de competências, a cooperação se revela nas chamadas competências comuns, consagradas no art. 23 da Constituição de 1988. Nas competências comuns, todos os entes da Federação devem colaborar para a execução das tarefas determinadas pela Constituição (...)" ${ }^{13}$

No Brasil, vê-se que a Constituição optou por competências concorrentes para a maior parte das políticas públicas, mas nota-se a preponderância do governo central, como observado por Marta Arretche: “a concentração de autoridade no governo federal caracteriza as relaçôes federativas na gestão das políticas, pois à União cabe o papel de principal financiador, bem como a normatização e coordenação das relaçôes intergovernamentais", ${ }^{14}$ evidenciando a tese formulada por Popitz do "poder de atração do maior orçamento". 15

São todos elementos complicadores para a formulação e execução de um planejamento orçamentário preciso em âmbito nacional, até mesmo porque o respeito à autonomia dos entes federados impede que se imponha a todos a integração

12 BERCOVICI, Gilberto. A descentralização de políticas sociais e o federalismo cooperativo brasileiro. Revista de Direito Sanitário, p. 15.

13 BERCOVICI, Gilberto. A descentralização de políticas sociais e o federalismo cooperativo brasileiro, p. 16; ROVIRA, Enoch Alberti. Federalismo y cooperación en la República Federal Alemana, p. 369.

14 ARRETCHE, Marta. Federalismo e políticas sociais no Brasil - problemas de coordenação e autonomia. Revista São Paulo em Perspectiva, p. 24.

15 Conforme menciona Fernando Casana Merino, em La autonomía financeira de las comunidades autónomas en matéria de gasto público (p. 25-30), texto sobre a qual se voltará a fazer referência no item 5.3 - "O poder de atração do orçamento central". 
necessária às políticas públicas e aos programas governamentais previstos. A operacionalização, em muitos casos, como se pode constatar, ocorre por meio de adesões dos entes federados, concretizadas por instrumentos de cooperação, como convênios, e financiadas por transferências voluntárias. Marta Arretche, ao tratar das políticas sociais no federalismo, observa que "a autoridade do governo federal para induzir as decisões dos governos locais, no sentido de que estas venham a coincidir com as suas próprias prioridades, permanece limitada, uma vez que estes detêm autonomia fiscal e política, tendo, portanto, condiçôes institucionais para não aderir às políticas federais". ${ }^{16}$

São muito variados os campos temáticos em que tal coordenação deve ocorrer em um Estado Federal. O fato de existir atualmente uma Administração plural, ${ }^{17}$ com uma multiplicidade de entes coexistindo, tanto no aspecto territorial (estados, regiōes, municípios etc.) quanto funcional (educação, saúde, justiça etc.), muitos com significativa autonomia, levanta a necessidade de coordenação, por meio do planejamento, nos mais variados setores da atuação política e administrativa das diversas partes autônomas de uma comunidade. ${ }^{18}$

Sendo assim, além da dimensão normativa, as relações políticas desempenham um papel fundamental, particularmente na federação brasileira, para o processo de planejamento. Como bem observado por Bercovici, o "processo de planejamento começa e termina no âmbito das relações políticas, ainda mais em um regime fede-

16 ARRETCHE, Marta. Federalismo e políticas sociais no Brasil - problemas de coordenação e autonomia, p. 19.

17 CABRAL, Nazaré da Costa. Programação e decisão orçamental. Da racionalidade das decisões orçamentais à racionalidade económica, p. 448, nota de rodapé 1.014, citando Vital Moreira.

18 O tema é de preocupação crescente na União Europeia com relação a diversos setores, no campo financeiro e orçamentário, destacando-se o tema dos déficits orçamentários. Assim como em diversos países, essa comunidade de países se preocupa fortemente com a consolidação e o controle das despesas totais dos entes federados, o que exige a coordenação de planos financeiros regionais com o plano nacional. Nazaré Cabral menciona a necessidade de coordenação da disciplina orçamentária entre os países da Comunidade Europeia, devendo os estados-membros ter uma estratégia comum ou convergir para uma disciplina e consolidação orçamentais, nos termos de compromissos assumidos em programas de estabilidade plurianuais ou em programas plurianuais de convergência (CABRAL, Nazaré da Costa. Programação e decisão orçamental. Da racionalidade das decisões orçamentais à racionalidade económica, p. 523). Ricardo Martner assevera que o planejamento plurianual se mostra fundamental e necessário para coordenar as ações dos entes federados no campo do endividamento público e na consolidação das contas do Estado. Estabelecer normas de sustentabilidade das dívidas públicas exige a construção de estratégias cooperativas, sendo o planejamento orçamentário plurianual, segundo o autor, a melhor solução institucional (Gestión pública y programación plurianual. Desafíos y experiencias recientes, p. 32). 
rativo, como o brasileiro, em que o planejamento pressupóe um processo de negociação e decisão políticas entre os vários membros da Federação e setores sociais". ${ }^{19}$

Ressalta ainda o mesmo autor a importância do planejamento no contexto federativo, mostrando que deficiências presentes no federalismo fiscal brasileiro decorrem da falta de planos ou programas de atuação definidos entre a União e os entes federados por ocasião da definição da descentralização de receitas e competências na Constituição de 1988, não sendo correto afirmar ter havido na época aumento de receitas sem os correspondentes encargos por parte dos entes subnacionais; em verdade, "as políticas sociais não sofreram mudanças qualitativas ou se deterioraram não pela sua concentração na esfera federal, mas pela total falta de planejamento, coordenação e cooperação no processo de descentralização". ${ }^{20}$

É importante identificar todas essas dificuldades relacionadas com o planejamento orçamentário governamental no contexto federativo, interessando particularmente analisar as fórmulas e os instrumentos jurídicos que são e podem ser utilizados para viabilizá-lo da melhor forma.

\subsection{PLANEJAMENTO ORÇAMENTÁRIO, COOPERAÇÃO E COORDENAÇÃO FEDERATIVA}

O planejamento orçamentário governamental está organizado juridicamente no Brasil em um sistema que abrange as três leis de natureza orçamentária: o Plano Plurianual; a Lei de Diretrizes Orçamentárias; e a Lei Orçamentária Anual - todas presentes no âmbito de cada unidade federativa.

Não obstante a existência de várias leis de planejamento governamental, que, embora tenham abrangência mais ampla, não se restringindo aos aspectos orçamentários do planejamento governamental, como o Plano Nacional de Educação e o Plano Nacional de Cultura, apenas para citar dois exemplos, é relevante observar que deve haver uma perfeita coordenação entre as diversas esferas de governo em matéria de planejamento orçamentário.

O Brasil é uma República Federativa, em que predomina um federalismo cooperativo, especialmente no âmbito financeiro. $\mathrm{O}$ federalismo fiscal brasileiro utiliza-se intensamente dos instrumentos de cooperação financeira, sendo as transferências intergovernamentais absolutamente fundamentais para viabilizar seu funcionamento.

19 BERCOVICI, Gilberto. Planejamento e políticas públicas, p. 146.

20 BERCOVICI, Gilberto. A descentralização de políticas sociais e o federalismo cooperativo brasileiro, p. 19-21. 
Inúmeras políticas públicas - não seria desarrazoado afirmar a maioria delas - são implementadas e funcionam com a participação de vários entes federados, de todas as esferas de governo.

Política pública, expressão cuja definição em termos jurídicos é difícil e complexa, tema sobre o qual já nos referimos anteriormente, ${ }^{21}$ é a forma pela qual se exteriorizam e materializam as açôes governamentais, e, de modo mais ou menos preciso, refletem-se nas leis orçamentárias de curto e médio prazos, exercendo papel fundamental no planejamento governamental. A multissetorialidade e a abrangência que ultrapassa a territorialidade das esferas de governo fazem com que o estudo do planejamento orçamentário governamental não prescinda da análise sob a óptica das políticas públicas.

No aspecto federativo, a implementação, a execução e a fiscalização das políticas públicas envolvem uma série de questões jurídicas e orçamentárias cuja análise merece ser mais aprofundada.

As políticas públicas dependem, no mais das vezes, com maior ou menor intensidade, de recursos públicos para se viabilizarem, razão pela qual se materializam nas leis orçamentárias. Isso pode ocorrer de forma clara e explícita, com a política pública coincidindo com um programa governamental perfeitamente caracterizado em planos plurianuais e leis orçamentárias, ou menos evidente, sendo executada com parte das dotações de programas que não representam exatamente a política pública financiada, que pode se valer de recursos oriundos de dotações incorporadas a outros programas, de mais de uma esfera de governo. Mais do que isso, não são financiadas apenas por recursos orçamentários, mas também por incentivos fiscais e financeiros, colaborações não governamentais e uma multiplicidade de possibilidades, como bem exposto por Maria Paula Bucci:

21 No item 1.3 - "Acepções do termo planejamento | Planejamento econômico, planejamento orçamentário, plano, programação, plano, programação, política pública” (Capítulo 1), quando mencionamos um dos conceitos expressos por Maria Paula Dallari Bucci, segundo a qual políticas públicas "são programas de ação governamental visando a coordenar os meios à disposição do Estado e as atividades privadas, para realização de objetivos socialmente relevantes e politicamente determinados" (Direito administrativo e políticas públicas, p. 241), ao qual se acrescenta também outra, que considera "um programa ou quadro de ação governamental, porque consiste num conjunto de medidas articuladas (coordenadas), cujo escopo é dar impulso, isto é, movimentar a máquina do governo, no sentido de realizar algum objetivo de ordem pública ou, na ótica dos juristas, concretizar um direito" (BUCCI, Maria Paula Dallari. O conceito de política pública em direito. Política públicas. Reflexões sobre o conceito jurídico, p. 14). Destacamos ainda o conceito de Regis de Oliveira: “Tomar providências para que os direitos se realizem, para que as satisfações sejam atendidas, para que as determinações constitucionais e legais saiam do papel e se transformem em utilidades aos governados é o que se rotula de politicas públicas" (Curso de direito financeiro, 2013, p. 327-328). 
"A alocação de meios para as políticas públicas abrange possibilidades amplas e diversas, além dos recursos orçamentários. Os meios públicos disponíveis para a implementação de uma política pública podem compreender também créditos fiscais, empréstimos públicos, cessão de uso de áreas ou bens públicos e recursos humanos e materiais". ${ }^{22}$

A transversalidade de boa parte das políticas públicas fica bem evidente no PPA federal 2012-2015, tendo sido explicitadas nas "agendas transversais", evidenciando claramente a necessidade de um planejamento orçamentário governamental compreensivo em torno do federalismo cooperativo, a se concretizar por meio de inúmeros instrumentos jurídico-orçamentários, como as transferências intergovernamentais, especialmente as voluntárias, que serão objeto de análise mais específica oportunamente.

Não há, pois, como estabelecer um planejamento orçamentário governamental sem levar em consideração a coordenação entre todas as esferas de governo, que deverão elaborar e executar suas leis orçamentárias de forma coesa entre si. O planejamento orçamentário governamental de cada esfera de governo exige, ao mesmo tempo, que se observem as peculiaridades e os interesses locais, regionais e nacionais, mas não prescinde do respeito ao planejamento das demais esferas de governo, especialmente aquelas com as quais o relacionamento financeiro é mais intenso, em que as transferências intergovernamentais são fundamentais para a condução da administração e o funcionamento adequado das várias políticas públicas em andamento e em implantação. No caso das políticas públicas operacionalizadas em âmbito nacional, com a participação de vários entes federados, mais ainda se faz presente a necessidade de respeitar um planejamento uniforme, coordenado e cooperativo.

A questão não é nova, e Guilherme Moojen, em texto publicado em 1959, mas que permanece ainda bastante atual, observa que a

"busca dos mesmos objetivos por duas ou três esferas de govêrno, cada uma planejando e agindo a seu modo, na mesma área física, tem ocasionado vultosos desperdícios de recursos financeiros, os quais, em última análise, são pagos pelo mesmo contribuinte. Urge, portanto, uma articulação dos esforços isolados, a fim de serem evitados gastos de administração paralelos ou em duplicata, e de serem obtidos, consequentemente, mais empreendimentos por cruzeiro dispendido". 23

Isso citando o exemplo norte-americano, em que a comissão especial nomeada em 1942 pelo Secretário do Tesouro dos Estados Unidos para avaliar as relações fiscais intergovernamentais concluiu em seu relatório que a coordenação e a cooperação

22 BUCCI, Maria Paula Dallari. Fundamentos para uma teoria jurídica das politicas públicas, p. 174.

23 MOOJEN, Guilherme. Orçamento público, p. 38. 
entre os entes federados é a solução para os problemas federativos observados, e não a subordinação e coerção, sendo esta coordenação o principal desafio a ser vencido. ${ }^{24}$

A gestão do planejamento, que envolve políticas públicas organizadas setorialmente, pelos diversos órgãos de governo, sendo muitas vezes multissetoriais, exige uma compatibilização com os aspectos territoriais da organização do Estado federal brasileiro. Essa compatibilização dos aspectos setoriais e territoriais no âmbito do planejamento faz de sua gestão um dos aspectos mais complexos, tanto no âmbito administrativo quanto jurídico, da organização do Estado.

O processo de planejamento governamental, desde sua formulação até sua implementação e avaliação, como bem ressaltado por Henrique Silveira, "acontece em meio a uma rede de relacionamentos interorganizacionais e sociais", sendo a gestão dessa rede de relacionamentos "afetada por fatores diversos - tecnológicos, culturais e sociais -, e é preciso fazer uso de estratégias que aumentem a efetividade da ação governamental". ${ }^{25}$

Uma das características mais marcantes do processo de planejamento orçamentário governamental é que a otimização de sua execução depende de uma capacidade de articular os diversos programas em torno de ações convergentes. Dada a diversidade temática dos setores em que opera a ação administrativa, esse processo depende da consideração da transversalidade dos temas e da multissetorialidade dos programas, organizando-se a atuação governamental de tal forma que a implementação dos programas encontre mecanismos que garantam sua eficácia. ${ }^{26} \mathrm{~A}$ multiplicidade temática representa mais um desafio ao planejamento orçamentário no ambiente federativo. $\mathrm{O}$ desdobramento dos programas de abrangência nacional em ações que dependem da participação de diferentes esferas de governo apresenta suas dificuldades, como já mencionado.

Fernando Rezende, com muita propriedade, chama a atenção para essa questão: "O sistema de coordenação das açôes governamentais implementado na década de setenta desempenhava um papel de fundamental importância para tornar efetiva a atividade de planejamento. Como a administração pública se organiza por setores, mas os problemas têm dimensão multissetorial, o sucesso do planejamento depende de uma boa sintonia das iniciativas a cargo dos órgãos setoriais, inclusive entidades da

24 MOOJEN, Guilherme. Orçamento público, p. 39-40.

25 SILVEIRA, Henrique Flávio Rodrigues da. Planejamento governamental e coordenação interorganizacional - um espaço para a aplicação de organizações virtuais no setor público? $\mathrm{Ca}$ dernos de Finanças Públicas, p. 127.

26 BRASIL. Ministério do Planejamento. Secretaria de Planejamento e Investimentos Estratégicos. Plano de Gestão do PPA 2004-2007, p. 17. 
Administração Indireta, relacionadas a um determinado objetivo do plano, bem como da sincronia com que tais iniciativas são implementadas. Nesse sentido, a criação de Conselhos Interministeriais com a atribuição de articular as ações relacionadas às principais áreas de concentração das políticas públicas, constitui um suporte relevante para o bom funcionamento de um sistema de planejamento".

E evidencia a dificuldade e a necessidade da boa coordenação federativa para o sucesso do planejamento:

"Uma outra dimensão da coordenação trata da questão federativa. Com a descentralização da gestão das principais responsabilidades do Estado no campo da promoção do desenvolvimento, uma gestão pública eficiente depende também de uma boa coordenação das ações executadas pelo governo federal, estados e municípios. A esse respeito, o esforço recente de introduzir a questão espacial nos trabalhos de elaboração do PPA 2008-2011 é um bom começo e demanda continuidade. A construção de instâncias de coordenação federativa é, todavia, uma tarefa complexa e delicada, pois requer a instituição de mecanismos e instrumentos que induzam a cooperação dos entes federados na execução de políticas e programas relacionados às prioridades estratégicas nacionais. Em decorrência do descompasso entre a descentralização da gestão e a centralização do financiamento, grande parte dos recursos federais é repassada a estados e municípios, que assumem a responsabilidade pelo seu gerenciamento. Como inexistem mecanismos eficientes, formais ou informais, que operem no sentido de promover a cooperação federativa na formulação e implementação das políticas públicas, a gestão de programas importantes para o país, como os que se inserem nas áreas urbanas e sociais, fica prejudicada. Dada a autonomia de que gozam os entes federados, a questão federativa afeta em particular a implementação de mudanças que tenham como propósito implantar normas e procedimentos voltados para a introdução de compromissos com resultados e a responsabilização dos gestores, na ausência de uma profunda reforma no modelo de federalismo fiscal". ${ }^{27}$

A coordenação intergovernamental, da qual o planejamento em um Estado federal não prescinde, necessita de instrumentos jurídicos que a assegurem, o que conduz à sua incorporação aos planos plurianuais. O plano de gestão do PPA federal 2004-2007, por exemplo, prevê a implementação dos "Pactos de Concertação", a serem firmados pelo Governo Federal, pelos Estados, pelo Distrito Federal e pelos Municípios, agrupados por sub-regiōes, para implementação de ações do PPA. Por meio desses pactos, "serão monitorados e analisados o desempenho físico e financeiro de cada uma das ações constantes do pacto e as restrições que podem dificultar ou impedir a concretização dos resultados pactuados", e o monitoramento "será feito por meio de monitores sub-regionais com o apoio dos gerentes setoriais

27 REZENDE, Fernando. Planejamento no Brasil: auge, declínio e caminhos para a reconstrução, p. 29. 
e analistas da $\mathrm{SPI}^{28}$ responsáveis pelos programas cujas ações constem dos Pactos de Concertação, de acordo com o modelo estabelecido para o monitoramento dos programas do Plano". ${ }^{29}$ Assim, "os Pactos de Concertação entre a União e os demais entes federativos representam um primeiro passo de compatibilização e expansão da clássica gestão setorial com a gestão que tem como referência o território", e os arranjos gerenciais propostos "permitem também uma gestão coordenada de grupo de programas, que aglutinem os setores e respectivos programas, selecionados, de acordo com as diretrizes das políticas Política Nacional de Desenvolvimento Regional; de desenvolvimento rural; de ordenamento do território; de meio ambiente e de desenvolvimento urbano e rede de cidades, entre outras" ${ }^{30}$ Os pactos de concertação configuram instrumentos que viabilizam a necessária integração do planejamento entre o PPA federal, os PPA estaduais, os PPA municipais e a sociedade, permitindo a convergência de prioridades de forma sincronizada, o que é fundamental para que o planejamento orçamentário governamental opere com a máxima eficiência, eficácia e efetividade. A utilização dos pactos entre entes federados como instrumentos para viabilizar o planejamento plurianual é prática adotada em muitos países, como vemos na Argentina, conforme menciona Horácio Corti: "La plurianualidad también fue considerada, como ya destacamos al analizar la forma federal, en diversos pactos intrafederales". ${ }^{31}$

Sob várias denominações, a coordenação da ação governamental entre os diversos níveis territoriais é reconhecida como necessária para o avanço dos processos de planejamento, administração e gestão de programas orçamentários dentro de determinado Estado. A tradição de independência e autonomia dos entes de um Estado que apresente descentralização territorial (e mesmo entre os diversos órgãos de um mesmo ente) exige a introdução de modelos de gestão que levem em conta a colaboração interorganizacional e intergovernamental para o sucesso das organizações. ${ }^{32}$

28 Secretaria de Planejamento e Investimentos Estratégicos do Ministério do Planejamento, Orçamento e Gestão.

29 BRASIL. Ministério do Planejamento. Secretaria de Planejamento e Investimentos Estratégicos. Plano de Gestão do PPA 2004-2007, p. 22-23.

30 BRASIL. Ministério do Planejamento. Secretaria de Planejamento e Investimentos Estratégicos. Plano de Gestão do PPA 2004-2007, p. 17.

31 CORTI, Horácio G. Derecho constitucional presupuestario, p. 332.

32 SILVEIRA, Henrique Flávio Rodrigues da. Planejamento governamental e coordenação interorganizacional - um espaço para a aplicação de organizaçōes virtuais no setor público?, p. 123-124. Nesse sentido, a tecnologia da informação oferece a oportunidade de mitigar o "conjunto de ilhas" de que muitas vezes consistem as organizações públicas. Idem, p. 127-9. 
Desta forma, tanto a variedade temática dos programas quanto sua execução regionalizada impõem a necessidade de sua articulação em torno de diretrizes de abrangência nacional, que se expressam particularmente nos chamados temas transversais e dependem do adequado monitoramento dos programas para atingir seus objetivos, nas mais variadas questóes marcadas pela transversalidade, como as relacionadas com direitos humanos e meio ambiente.

A tarefa de institucionalização desses e de outros tantos temas envolve todas as esferas de governo, dada a descentralização dos programas. No Brasil, a proposta do Ministério do Planejamento é fazer com que, para atingi-la, se criem, nos Ministérios diretamente envolvidos, responsáveis pela condução dos programas e pelo atingimento das metas de transversalidade, órgãos e programas que funcionem como espaço de coordenação e sirvam como ferramenta de monitoramento e transparência, permitindo que os órgãos governamentais divulguem e exponham, principalmente de maneira virtual, demonstrativos dos andamentos dos programas. ${ }^{33}$

No Plano Plurianual federal 2012-2015, como pode ser visto em mais detalhes em item próprio a respeito do tema, houve a criação dos "programas temáticos", cuja função é justamente organizar as políticas públicas para orientar a ação governamental de forma que permita uma boa gestão, com monitoramento e avaliação, abrangendo a transversalidade, a multissetorialidade e a territorialidade, ${ }^{34}$ sendo estruturadas as chamadas "agendas transversais", organizando-se os programas temáticos em torno dos oito temas previstos no Plano Brasil Maior (Comércio Exterior, Investimentos, Inovação, Formação e Qualificação Profissional, Produção Sustentável, Competitividade de Pequenos Negócios, Ações Especiais em Desenvolvimento Regional e Bem-Estar do Consumidor).

No caso brasileiro, o governo federal dispõe de instrumentos para coordenar as políticas nacionais, apesar das tendências dispersivas decorrentes do sistema tributário e das coalizões partidárias. Essa articulação é feita a despeito do sistema tributário e do sistema partidário, este último altamente fragmentado, ${ }^{35}$ que são desfavoráveis à coordenação de políticas e dependem predominantemente de ou-

33 BRASIL. Ministério do Planejamento. Secretaria de Planejamento e Investimentos Estratégicos. Plano de Gestão do PPA 2004-2007, p. 21-22.

34 BRASIL. Ministério do Planejamento, Orçamento e Gestão. Secretaria de Planejamento e Investimentos Estratégicos. Orientações para a elaboração do Plano Plurianual 20122015, p. 12.

35 ARRETCHE, Marta. Federalismo e políticas sociais no Brasil - problemas de coordenação e autonomia, p. 20. 
tros mecanismos institucionais do governo federal para induzir a ação de governos subnacionais no sentido desejado. ${ }^{36}$

O recente Estatuto da Metrópole (Lei n. 13.089, de 12 de janeiro de 2015) prevê instrumentos que denotam avanço na questão, se bem implementados. Há um claro reconhecimento da necessidade de articulação em termos de planejamento orçamentário, como se vê ao prever o sistema de "governança interfederativa", por meio do qual se viabilizará o "compartilhamento de responsabilidades e ações entre entes da federação em termos de organização, planejamento e execução de funções públicas de interesse comum" (art. $\left.2^{\circ}, \mathrm{IV}\right)$, que tem como uma de suas diretrizes específicas a "compatibilização dos planos plurianuais, leis de diretrizes orçamentárias e orçamentos anuais dos entes envolvidos na governança interfederativa” (art. 7º, VI).

Em alguns casos no Brasil, há um sistema jurídico de planejamento governamental bem organizado e sistematizado, ainda que não plenamente implantado, como é o caso do planejamento no setor de Educação. Este tema será analisado em item próprio, cabendo referência nesse ponto aos aspectos relevantes para demonstrar a organização do sistema.

Prevê-se para o setor o Plano Nacional de Educação (PNE), de duração decenal, conforme expressamente consta do art. 214 da Constituição. Veiculado por lei de natureza nacional, portanto aplicável a todos os entes da federação, estabelece diretrizes para o setor que incluem aspectos orçamentários, não se restringindo a eles, por ter abrangência muito mais ampla.

A partir da vigência do primeiro PNE (Lei n. 10.172, de 9 de janeiro de 2001), para o período de 2001 a 2010, impôs-se aos Estados, ao Distrito Federal e aos Municípios o dever de elaborar os respectivos planos decenais correspondentes (art. 2o), estando o dos Estados em consonância com o PNE, e o dos Municípios também coerentes com o plano do respectivo estado, compondo os três documentos um conjunto integrado quanto a objetivos, prioridades, diretrizes e metas estabelecidos e articulado nas ações, de modo a se somarem os esforços das três esferas para atingir as metas estabelecidas, sob uma coordenação em âmbito nacional e coordenações nos Estados, no Distrito Federal e nos Municípios exercidas pelos respectivos órgãos responsáveis pela Educação (Anexo, item VI - Acompanhamento e avaliação do plano).

Estabelece-se expressamente (art. $5^{\circ}$ do PNE 2001-2010) que "os planos plurianuais da União, dos Estados, do Distrito Federal e dos Municípios serão elaborados

36 ARRETCHE, Marta. Federalismo e políticas sociais no Brasil - problemas de coordenação e autonomia, p. 17-18. 
de modo a dar suporte às metas constantes do Plano Nacional de Educação e dos respectivos planos decenais", deixando inequívoca a obrigação de haver uma perfeita coordenação entre todas as leis, de modo a formar um sistema lógico e coeso.

Interessante notar que se reconhece claramente a importância de aprimorar o regime de colaboração federativa, fundamental para a gestão eficiente do sistema, tendo em vista a partilha de responsabilidades entre os entes federados decorrentes do federalismo presente no setor educacional:

"Para que a gestão seja eficiente há que se promover o autêntico federalismo em matéria educacional, a partir da divisão de responsabilidades previstas na Carta Magna. A educação é um todo integrado, de sorte que o que ocorre num determinado nível repercute nos demais, tanto no que se refere aos aspectos quantitativos como qualitativos. Há competências concorrentes, como é o caso do ensino fundamental, provido por Estados e Municípios. Ainda que consolidadas as redes de acordo com a vontade política e capacidade de financiamento de cada ente, algumas ações devem envolver Estados e Municípios, como é o caso do transporte escolar. Mesmo na hipótese de competência bem definida, como a educação infantil, que é de responsabilidade dos Municípios, não pode ser negligenciada a função supletiva dos Estados (art. 30, VI, $\mathrm{CF}$ ) e da União (art. 30, VI, CF e art. 211, $\$ 1^{\circ}$, CF). Portanto, uma diretriz importante é o aprimoramento contínuo do regime de colaboração. Este deve dar-se, não só entre União, Estados e Municípios, mas também, sempre que possível, entre entes da mesma esfera federativa, mediante ações, fóruns e planejamento interestaduais, regionais e intermunicipais". ${ }^{37}$

No setor de Saúde, também objeto de análise específica (item 7.3), há um sistema organizado de planejamento governamental, que, à semelhança do que ocorre na área da Educação, é abrangente, não se limitando aos aspectos orçamentários.

As ações e os serviços públicos de saúde constituem um Sistema Único de Saúde (SUS), rede regionalizada e hierarquizada, organizada de acordo com as diretrizes constitucionais (CF, art. 198). A Lei n. 8.080, de 1990, atribuiu à direção nacional do SUS a competência para elaborar o Planejamento Estratégico Nacional no âmbito do SUS, com a cooperação técnica dos Estados, do Distrito Federal e dos Municípios (art. 16, XVIII).

O processo de planejamento e orçamento do SUS é "ascendente”, ou seja, vai do nível local até o central, ouvindo-se os órgãos deliberativos e compatibilizando-se as necessidades da política de saúde com a disponibilidade de recursos nos planos de saúde dos Municípios, Estados, Distrito Federal e União (Lei n. 8.080/1990, art. 36).

37 Lei n. 10.172/2001 (PNE 2001-2010), item V (Financiamento e gestão), subitem 11.2 (Diretrizes). 
Cada ente federado deverá elaborar seu próprio Plano de Saúde, sob pena de ficar impedido de receber transferências de recursos para financiar ações na área da Saúde (Lei n. 8.080/1990, art. 36, \$2º).

Em 2005, cria-se o PlanejaSUS, sistema de planejamento do SUS de atuação contínua, articulada, integrada e solidária das áreas de planejamento das três esferas de gestão desse sistema, em que se definem as responsabilidades das áreas de planejamento de cada uma das esferas de gestão, de modo a permitir o funcionamento harmônico, por meio de pactos de saúde. ${ }^{38}$

Há, portanto, um planejamento para o setor que está juridicamente organizado, de forma sistemática e hierarquizada, com delimitações precisas de atribuições, tanto na elaboração quanto na execução do planejamento, permitindo uma cooperação federativa harmônica entre os entes federados.

Outros setores também serão objeto de análise mais detalhada, ficando apenas esse registro ilustrativo das áreas de Educação e Saúde, em face de sua relevância no âmbito dos direitos sociais.

\subsection{COORDENAÇÃO FEDERATIVA E AS TRANSFERÊNCIAS INTERGOVERNAMENTAIS. O PAPEL DAS TRANSFERÊNCIAS VOLUNTÁRIAS}

Os instrumentos para operacionalizar essa coordenação federativa do sistema de planejamento orçamentário governamental são múltiplos e variados, e as soluções para dirimir os conflitos também o são.

O federalismo fiscal brasileiro tem nas transferências intergovernamentais seu principal instrumento, e encontramos desde as transferências intergovernamentais que operacionalizam partilhas de receitas, especialmente tributárias, até as transferências voluntárias, destinadas principalmente à implementação de programas governamentais específicos.

Muitas políticas públicas se viabilizam pela combinação do uso dos vários tipos de transferências, de modo que sejam aproveitadas as vantagens oferecidas por elas, para conseguir uma adequada distribuição dos recursos de acordo com os objetivos a serem alcançados e sem prejuízo à segurança jurídica, garantindo o dinheiro necessário aos atores envolvidos e permitindo o planejamento das ações governamentais do setor.

38 BRASIL. Ministério da Saúde. Secretaria Executiva. Subsecretaria de Planejamento e Orçamento. Sistema de planejamento do SUS. Uma construção coletiva. Organização e funcionamento, p. 27. 
As várias modalidades de transferências intergovernamentais que se identificam no sistema brasileiro podem ser úteis com a finalidade de permitir uma coordenação entre os entes da federação de modo a assegurar a execução do que foi estabelecido pelo planejamento orçamentário de cada um.

As transferências intergovernamentais representam um importante papel na implementação das políticas públicas, garantindo um padrão mínimo de qualidade nos serviços públicos prestados, independentemente da região do país, assegurando, ainda, maior homogeneidade, evitando desequilíbrios horizontais. ${ }^{39}$

O planejamento da ação governamental depende de um bem estruturado mecanismo de transferências intergovernamentais, que deve seguir alguns princípios fundamentais, como bem sistematizam Ahmad e Craig: ${ }^{40}$

a) predomínio da preocupação com a estabilidade, devendo o governo central manter sua capacidade de controlar a economia;

b) desenvolver um modelo macroeconômico, pois as transferências não devem ser negociadas aleatoriamente, mas em um contexto de um planejamento governamental de médio prazo, abrangendo pelo menos três anos, com previsões de renda e gasto dos entes federados em seus vários níveis;

c) os ajustes devem permitir flexibilidade, com possibilidades de revisões, ajustando-se às circunstâncias;

d) os objetivos das transferências devem ser claros, transparentes e mensuráveis, permitindo o controle e fiscalização;

e) a inter-relação entre as transferências deve ser levada em consideração, e avaliado o impacto geral das transferências, bem como a consistência entre as transferências condicionadas e as incondicionadas;

f) simplicidade, especialmente nas transferências condicionadas, cujos objetivos devem ser claros e facilmente compreensíveis;

g) as alternativas devem ser examinadas, tendo em vista haver múltiplas alternativas para o financiamento das diversas políticas públicas, que precisam ser reavaliadas.

39 DUARTE, Ângelo José M.; SILVA, Alexandre Manoel A.; LUZ, Everaldo M.; GERALDO, José Carlos. Transferências fiscais intergovernamentais no Brasil: uma avaliação das transferências federais, com ênfase no Sistema Único de Saúde, p. 8.

40 AHMAD, Ehtisham; CRAIG, John. Intergovernmental transfers. In: TER-MINASSIAN, Teresa (Ed.). Fiscal federalismo in theory and practice, p. 93-94. 
A intensa inter-relação financeira entre os entes federados em Estados organizados na forma federativa, decorrentes da necessária cooperação para a implementação e execução de grande parte das mais importantes políticas públicas, faz das transferências intergovernamentais, como já ressaltado, instrumentos fundamentais não somente para a viabilização da operacionalidade do sistema, mas também para o planejamento da ação governamental.

Todo planejamento da ação governamental, para tornar-se viável, com segurança jurídica, depende da arquitetura de um sistema de transferências intergovernamentais que seja adequado às características de cada política pública e dos próprios entes federados, uma vez que, no mais das vezes, os recursos com os quais estes implantarão e executarão as ações governamentais serão essencialmente quando não totalmente - obtidos por meio das transferências intergovernamentais. Daí a importância de se observarem os princípios enumerados por Ahmad e Craig ora mencionados.

É importante a construção de um modelo de transferências intergovernamentais perfeitamente ajustado aos propósitos da política pública, que seja adequado às características do federalismo cooperativo existente, levando-se em consideração as potencialidades dos entes federados envolvidos, que permita, ao mesmo tempo, o controle por parte do ente central (ou outro que venha a ser o responsável pela política pública) e a dotação da flexibilidade necessária para que se adapte às circunstâncias de tempo, modo e local que possam surgir ao longo da execução. É fundamental a clareza dos objetivos e critérios envolvidos, permitindo não só que a transferência dos recursos se dê de forma transparente, mas também que facilite a implantação e execução das ações governamentais, o que colaborará decisivamente para que os resultados sejam plenamente alcançados, com a fiscalização pelos órgãos públicos e pelos mecanismos de controle social.

O sistema de federalismo cooperativo no Brasil prevê um amplo uso dos vários modelos e espécies de transferências intergovernamentais, compondo um sistema de federalismo fiscal complexo. As transferências intergovernamentais são fundamentais para aperfeiçoar a distribuição de recursos entre os entes federados, bem como para financiar muitas das mais importantes políticas públicas em que há participação de todos eles, como é o caso de saúde e educação, entre outras. Em todos os casos, o planejamento governamental, destacadamente o planejamento orçamentário dos entes envolvidos, estará estreitamente vinculado ao sistema arquitetado de transferências intergovernamentais, uma vez que os recursos deverão constar nos orçamentos de cada unidade federada, tanto na previsão de receitas daqueles que receberão os recursos quanto na previsão de despesas dos entes de cujos orçamentos os recursos sairão para financiar os programas envolvidos. 
Mais do que isso, o sistema de transferências influenciará decisivamente no planejamento da ação governamental, pois a previsão não só de curto, mas também de médio prazo, é fundamental para conferir segurança jurídica e permitir a adequação de todas as administrações públicas envolvidas na execução das tarefas relacionadas com as ações governamentais envolvidas.

As transferências destinadas a operacionalizar partilhas de receitas, como encontramos nos Fundos de Participação dos Estados e Distrito Federal (FPE) e dos Municípios (FPM) são fundamentais para aperfeiçoar a redistribuição de recursos em nossa federação, garantindo, assim, receitas livres, não condicionadas, aos entes beneficiários, que podem ser utilizadas para financiar os programas que cada um deles fez constar de suas leis orçamentárias. Dada a característica de serem receitas permanentes, propiciando segurança no recebimento, em valores razoavelmente constantes, podem ser utilizadas para financiar políticas públicas próprias de cada ente, tanto de curto quanto de médio e longo prazos.

Maior relevância ainda têm os sistemas de transferências intergovernamentais setoriais, que se operacionalizam por transferências obrigatórias condicionadas, as quais permitem o financiamento de políticas públicas específicas, assegurando-lhes recursos em caráter permanente e constante, viabilizando e conferindo maior segurança jurídica. É o caso, por exemplo, das transferências para as áreas de Educação e Saúde, que contam com um desenho de federalismo fiscal próprio, com fundos e transferências intergovernamentais previstas na Constituição e na legislação infraconstitucional nacional, os quais são objeto de análise mais detalhada em item específico.

O que tem mostrado ser o principal instrumento de cooperação federativa e coordenação entre os entes da federação na implementação de políticas públicas compartilhadas são as chamadas transferências voluntárias, recursos transferidos entre entes da federação a título de cooperação, auxílio ou assistência financeira (LRF, art. 25).

A entrega de recursos das transferências voluntárias no Brasil é no mais das vezes operacionalizada por meio da celebração de convênios, instrumentos destinados a efetivar a execução descentralizada dos programas de trabalho governamentais, por meio das transferências a título de contribuição, auxílio ou subvenção social.

O sistema de financiamento de grande parte das políticas públicas no Brasil por meio de transferências intergovernamentais voluntárias é útil e eficiente para viabilizá-las, apresentando vantagens importantes, como a de permitir que os entes federados tenham respeitadas suas autonomias, uma vez que lhes é facultado aderir aos programas governamentais que as propiciam. 
Causam, no entanto, algumas dificuldades no âmbito do planejamento orçamentário governamental.

A mais relevante é a sua inserção no sistema de planejamento dos entes federados subnacionais, pois, não obstante a obrigatoriedade da contabilização dos recursos de convênios nos orçamentos das entidades concedentes e convenentes, constata-se uma insegurança jurídica a que ficam sujeitas, ante a incerteza quanto à sua efetiva concretização, bem como à própria continuidade no recebimento, tendo em vista o que se tem observado na prática arraigada no federalismo fiscal brasileiro. A instabilidade dos fluxos das transferências de recursos federais configura um dos grandes problemas decorrentes da forte centralização dos recursos na União, como bem observou Fernando Rezende. ${ }^{41}$

Instrumentos de barganha política, muitas vezes as transferências governamentais são utilizadas para obter apoio político à base de sustentação do governo. Em um sistema presidencialista multipartidário, a cooptação de apoios para compor o governo, em nosso presidencialismo de coalizão, faz com que esses instrumentos se tornem úteis para viabilizar essa prática. Vê-se ser comum que as transferências voluntárias sejam inseridas no orçamento, na fase administrativa de elaboração da peça orçamentária do ente federado que detém o seu controle, em função de ajustes políticos momentâneos. Outras vezes, aparecem na fase legislativa de elaboração do orçamento público, por meio de emendas parlamentares, também obtidas por vezes após negociação fundada em interesses de natureza política. Aprovado o orçamento, é conhecida a prática de submeterem-se as dotações que as contemplam ao contingenciamento, cuja liberação condiciona-se à conjuntura política, evidenciando a falta de segurança a que ficam sujeitos os recursos das transferências voluntárias. ${ }^{42}$

As questôes de natureza política influenciam também nas transferências voluntárias de modo a dificultar o planejamento em relação à previsão e mesmo execução desses valores, em face da conhecida divisão de cargos na administração pública para composição política, ante o sistema de governo de coalizão vigente. ${ }^{43}$

41 REZENDE, Fernando. A política e a economia da despesa pública. Escolhas orçamentárias, ajuste fiscal e gestão pública: elementos para o debate da reforma do processo orçamentário, capítulo 4, especialmente p. 142-152.

42 Questão sobre a qual já houve referência em textos de minha autoria: "Transferências voluntárias geram desequilíbrio federativo", "Emendas ao orçamento e o desequilíbrio de poderes", "Aprovação do 'orçamento impositivo' é insuficiente para dar credibilidade à lei orçamentária" (todos publicadas no livro Levando o direito financeiro a sério, p. 19-22 e 231-234 e 235-240, respectivamente). Esse mecanismo sofre substancial alteração com as emendas que alteraram o sistema do "orçamento impositivo" (EC 86/2015, e 100, 102 e 105, estas últimas de 2019).

43 Alexsandra Dallaverde bem demonstra a influência política na operacionalização das transferências voluntárias (As transferências voluntárias no modelo constitucional brasileiro, p. 303-305). 
Apenas para ilustrar, é notório que o prefeito de um município possa ter maior afinidade, até mesmo por pertencer ao mesmo partido, com o ministro ou servidor da alta administração que comanda órgão responsável pela concessão de transferências voluntárias, o que evidentemente facilitará a obtenção dos recursos enquanto perdurar essa situação. E, por sua vez, enfrentará obstáculos em conseguir transferências voluntárias de ministérios ou órgãos cujo comando é exercido por autoridades de partidos políticos adversários. Circunstâncias políticas muitas vezes alteram a composição de ministérios e órgãos da administração, com trocas de comando motivadas por necessidades de reajustes na composição da base de sustentação do governo, e tudo isso pode alterar repentinamente a concessão ou mesmo liberação de recursos já concedidos por transferências voluntárias. São todos fatores de difícil previsão, inviabilizando contar com os recursos dessas fontes de forma segura, que permita contemplá-los no sistema de planejamento orçamentário governamental com a precisão e a segurança desejáveis.

Nesse contexto, inviabiliza-se que a contabilização, pelos entes subnacionais beneficiários das transferências voluntárias, das receitas que elas podem representar na peça orçamentária, e mesmo no Plano Plurianual, sejam consideradas recursos cujo recebimento é certo. As açôes governamentais a serem realizadas pelo ente beneficiário da transferência ficam altamente prejudicadas, dada a inviabilidade de prever com razoável segurança e credibilidade o efetivo recebimento do recurso, o que compromete todo e qualquer planejamento, de curto ou médio prazos, que dependa dos referidos recursos.

Diante da constatação de que o federalismo fiscal brasileiro, especialmente no que tange aos municípios, mostra-se seriamente comprometido, tendo em vista a forte centralização de recursos na esfera federal, e subsidiariamente estadual, fazendo com que as mais importantes políticas públicas, bem como obras de infraestrutura, dependam de recursos de transferências voluntárias, não se mostra viável um planejamento orçamentário governamental dos entes subnacionais dotado de credibilidade.

No caso dos entes subnacionais, especialmente municípios, em que as despesas de capital, dotadas de relevância para o planejamento de médio e longo prazo, e que devem ser contempladas nos planos plurianuais, são essencialmente financiadas por transferências voluntárias, a questão se torna mais grave.

Os municípios brasileiros vivenciam situação financeira difícil, em que as receitas oriundas de arrecadação própria, somadas às transferências intergovernamentais automáticas, regra geral financiam, no máximo, as despesas correntes. Políticas públicas fundamentais, como de educação e saúde, são basicamente 
financiadas pelos sistemas de transferências intergovernamentais próprios de cada setor, tornando-os dependentes desses recursos transferidos para conduzir as referidas políticas públicas.

As despesas de capital, destinadas a obras de infraestrutura e outras relevantes ações governamentais na esfera local, acabam sendo financiadas por meio de transferências voluntárias, que, como já mencionado, têm estado sujeitas a uma ampla gama de incertezas, tanto na concretização dos atos que a viabilizam quanto na posterior execução, com a efetiva liberação dos recursos. Sendo essa modalidade de despesas a que mais importa para o planejamento governamental, esse quadro não colabora para que se construa um sistema de planejamento seguro e eficiente.

A partir de então, vê-se a importância da efetiva observância das normas de planejamento governamental, especialmente no âmbito orçamentário. É imprescindível para a boa gestão pública que as normas que instituem o planejamento orçamentário governamental, com destaque para os PPA, sejam dotadas de credibilidade e impositividade. Previstos recursos federais em um PPA federal (em uma hipótese exemplificativa) para transferências voluntárias a um ente subnacional, destinado a uma finalidade específica, como a implantação ou continuidade de determinada política pública, o recurso há de ser efetivamente entregue no prazo estipulado, independentemente de injunções políticas de caráter momentâneo e transitório. Sem esse respeito à norma planejadora plurianual, não há como viabilizar, com segurança jurídica, e sem desperdício de recursos de toda natureza (materiais, humanos, infraestrutura etc.), qualquer política pública.

\subsection{O PODER DE ATRAÇÃO DO ORÇAMENTO CENTRAL}

Em uma federação, a Constituição prevê os objetivos fundamentais do Estado e princípios que devem ser observados, cabendo ao governo central, no exercício de suas competências, agir de forma integrada com os demais entes federados, para que esses objetivos sejam alcançados. ${ }^{44}$

Nesse percurso, é necessário compatibilizar as ações do governo central com o respeito à autonomia dos entes subnacionais.

44 Como bem expressa Heleno Torres, "No federalismo, devido à Constituição rígida comum, centros de poder, dotados de autonomia, desprovidos de hierarquia em relação aos outros, diferenciados apenas pelas atribuições de competências, convergem para uma unidade, que é a organização do Estado, uma estatalidade que não existiria fora dessa unidade. Neste contexto, a função da Constituição Financeira será aquela de integrar a unidade central e as periféricas para um seguro e permanente financiamento do Estado" (Direito constitucional financeiro. Teoria da constituição financeira, p. 245). 
Como se tem visto e se verá ainda ao longo deste trabalho, há uma multiplicidade de possibilidades de operacionalizar e viabilizar essas ações em regime de cooperação e colaboração, interessando particularmente para o tema que abordado os aspectos financeiros, ainda que se utilizem outros instrumentos, como o compartilhamento de recursos humanos e infraestrutura.

No mais das vezes, essa colaboração ocorre entre os entes da federação de forma voluntária, implantando-se a política pública, de caráter nacional ou regional, mediante a adesão dos entes federados interessados em compartilhar os benefícios dela advindos, caso em que são celebrados os pactos, na forma de acordos, convênios ou outro instrumento que a formalize, a partir do qual são feitas as transferências de recursos e cumpridas as obrigações assumidas pelas partes.

É o que se constata, por exemplo, no caso brasileiro, do planejamento governamental no setor de cultura, de âmbito nacional. ${ }^{45}$ Há um Plano Nacional de Cultura, que criou o Sistema Nacional de Cultura, com recursos a serem distribuídos por meio do Fundo Nacional de Cultura aos Estados e Municípios que aderirem ao sistema, formalizado mediante um "acordo de cooperação federativa”. Há, portanto, como expressamente estabelece a legislação, uma vinculação voluntária entre os entes federados (Lei n. 12.343/2010, art. $3^{\circ}, \$ 2^{\circ}$ ), que cria obrigaçóes como a de elaborar o respectivo plano decenal de cultura do ente que aderiu ao sistema, bem como a de fazer constar das respectivas leis orçamentárias os recursos a serem destinados à execução das metas estabelecidas para o setor (Lei n. 12.343/2010, art. $4^{\circ}$ ).

Mas nem sempre há tais cooperação e coordenação juridicamente formalizadas, e a implementação de políticas públicas pode eventualmente gerar dificuldades e conflitos entre os entes federados.

Fernando Casana Merino, ao discorrer sobre a autonomia financeira das comunidades autônomas espanholas, menciona a tese do "poder de atração do maior orçamento" como um possível argumento para dirimir controvérsias entre os entes federados em matéria de federalismo fiscal, reconhecendo a supremacia do poder central, que tem o maior orçamento, sobre os entes subnacionais, quando se trata de implementar políticas públicas de sua alçada de competência.

Mostra que, nos Estados Unidos, o sistema de federalismo cooperativo passou a predominar a partir do crescimento das receitas do poder central com a criação do imposto de renda federal pela Emenda XVI, em 1913, e se intensificaram os gastos federais por meio de transferências intergovernamentais condicionadas,

45 Tema que será objeto de análise específica no item 7.2. 
aumentando o poder de gastos pelo governo central, validando a tese do "poder de atração do maior orçamento", formulada por Johannes Popitz na Alemanha em 1927. A tese de Popitz era de que o poder central acaba assumindo gastos maiores do que aqueles previstos na Constituição, o que se evidenciava nos Estados Unidos, superando a fórmula federativa dos princípios do federalismo dualista e fortalecendo o federalismo cooperativo. O poder central é dotado de poderes implícitos para prover o bem-estar geral dos Estados Unidos, e, com isso, podia adotar medidas de natureza financeira, promovendo despesas públicas independentemente de competência expressamente atribuída pela Constituição. Merino menciona a jurisprudência da Suprema Corte dos Estados Unidos, que, a partir de 1936, decidiu pela possibilidade de o Poder Legislativo autorizar despesas no interesse público, ainda que não houvesse norma constitucional expressa que lhe atribuísse tal competência. Assim, são legítimas as transferências intergovernamentais condicionadas aos entes subnacionais, até mesmo por serem de aceitação facultativa, mesmo que se refiram a matérias constitucionalmente de competência dos referidos entes subnacionais. Relata que, nas décadas seguintes a 1945, a política de transferências condicionadas baseada na aprovação de planos estatais de investimentos teve vários modelos. No período do Presidente Johnson, houve o chamado "federalismo criativo", quando se expandiram os beneficiários das transferências, aumentando as exigências para a concessão e o controle das transferências pelas autoridades federais. Na administração Nixon, houve uma partilha maior dos recursos, com a transformação de 129 transferências em seis programas de partilha de receitas, em que a finalidade dos recursos era fixada em termos mais amplos, deixando uma elevada margem de discricionariedade aos beneficiários; essas reformas, porém, não foram inteiramente aceitas pelo Congresso, o que impediu a recuperação da autonomia dos Estados em matéria de gasto público. Com a Presidência Reagan, surge o "novo federalismo", propiciando-se a redução da capacidade de influência do governo federal, restituindo-se a autonomia financeira dos Estados. No entanto, com a recusa do Congresso, em 1982, da proposta apresentada por Reagan, que continha medidas destinadas a recuperar a autonomia financeira dos Estados, houve pressão da classe empresarial para uma maior regulação das transferências, com centralização dos poderes decisórios. Com isso, conclui Merino, vê-se ser muito difícil suprimir o controle central sobre as transferências e a restituição aos Estados da autonomia sobre as despesas públicas nas matérias de sua competência. Observa ainda que, nos últimos anos, houve diminuição das transferências condicionadas, base do federalismo cooperativo. No entanto, ante a constatação do aumento dos gastos federais, admite-se uma maior interferência do governo central nos gastos dos Estados, por meio de regulações diretas, como forma de controlar os gastos dos Estados, 
e a aprovação de normas mais rígidas para punir os Estados em caso de transgressóes, e sanções civis e penais aos funcionários públicos. Conclui que a tese do poder de atração do maior orçamento segue presente no exercício do poder de gasto nos Estados Unidos, estendendo-se essa teoria para os Estados Federais e estados de estrutura plural ou composta, como é o caso da Espanha. ${ }^{46}$

Tendo em vista que muitas vezes as políticas públicas executadas no âmbito do federalismo cooperativo, com a participação de mais de uma esfera de governo, não têm suas exatas delimitações de atribuições expressas de forma precisa na legislação, há que se estabelecer critérios que permitam dirimir eventuais controvérsias em caso de conflitos, caso ocorram. Em sendo uma política pública de interesse público relevante, cuja implementação e/ou execução se mostre necessária para satisfazer a determinadas necessidades públicas, deve-se reconhecer o poder do ente federado mais central de impor as condições mínimas para gerir a política pública, com a necessária colaboração dos entes da federação cuja participação se mostre imprescindível para que seja bem-sucedida. É o caso, para citar um exemplo hipotético, de controle de endemias. Havendo necessidade de cooperação federativa, e sendo imperiosa a implementação da política por evidente interesse público de toda a nação ou região, não há como aceitar eventual autonomia de qualquer ente federado para não integrar o sistema de cooperação (financeira ou de outra natureza) com vistas a combater esse problema de saúde pública. Há prevalência do ente detentor do orçamento central, capaz de impor aos demais a realização dos atos necessários para que a política pública atinja os resultados almejados. Abrangendo mais de um ente federado, evidentemente somente ao ente mais central é possível planejar a política pública e conduzir sua execução.

46 MERINO, Fernando Casana. La autonomía financeira de las comunidades autónomas en matéria de gasto público, p. 242-31. 